\title{
Patterns and determinants of effective coverage of routine maternal and newborn health visits in Nepal: Analysis of the 2016 Demographic and Health Survey
}

Resham Khatri ( $\nabla$ rkchettri@gmail.com )

Health Social Science and Development Research Institute

Jo Durham

Queensland University of Technology

Rajendra Karkee

BP Koirala Institute of Health Sciences

Yibeltal Assefa

University of Queensland

\section{Research Article}

Keywords: Effective coverage, health facility, maternal and newborn health, determinants, Nepal

Posted Date: June 4th, 2021

DOI: https://doi.org/10.21203/rs.3.rs-347305/v1

License: (c) (i) This work is licensed under a Creative Commons Attribution 4.0 International License.

Read Full License 
1 Patterns and determinants of effective coverage of routine maternal and

2 newborn health visits in Nepal: Analysis of the 2016 Demographic and Health

3 Survey

4

5 Resham B Khatri ${ }^{1,2 *}$, Jo Durham ${ }^{1,3}$, Rajendra Karkee ${ }^{4}$, Yibeltal Assefa ${ }^{1}$

6

7 ' ${ }^{1}$ School of Public Health, Faculty of Medicine, University of Queensland, Brisbane,

8 Australia.

$9 \quad{ }^{2}$ Health Social Science and Development Research Institute, Kathmandu, Nepal.

$10{ }^{3}$ School of Public Health and Social Work, Queensland University of Technology,

11 Brisbane, Australia.

$12{ }^{4}$ School of Public Health and Community Medicine, BP Koirala Institute of Health

13 Sciences, Dharan, Nepal.

14

*Corresponding author (E-mail): rkchettri@gmail.com

17 Word Count: (excluding title page, abstract, end materials, figure legends, references)

DISCLAIMER: Views presented in this article are solely those of the authors, and do not represent the views, interests, or funded work of the organisations where authors 21 affiliated. 
33 Abstract

\section{Background}

Antenatal care (ANC) visits, institutional delivery, and postnatal care (PNC) visits are vital for improved health of mothers and newborns. Access of these routine maternal and newborn health $(\mathrm{MNH})$ visits have increased in the last few decades in Nepal; however, little is known on the effective uptake (including timely, skilled, frequent, and adequate care) of essential $\mathrm{MNH}$ interventions during those visits. This study examined the patterns of effective coverage (EC) of routine $\mathrm{MNH}$ visits and their determinants in Nepal.

\section{Methods}

A secondary analysis was conducted taking data from the Nepal Demographic and Health Survey (NDHS) 2016. The study included 1,978 women aged 15-49 years who had a live birth in the two years preceding the survey. Three outcome variables were $\mathrm{EC}$ of i) at least $4 A N C$ visits, ii) institutional delivery, and iii) first PNC visit for newborns and mothers within 48 hours of childbirth. The independent variables included several structural, intermediary and health system factors. Binomial logistic regression analysis was conducted, and the magnitude of EC was reported as odds ratio (OR) with $95 \%$ confidence intervals (Cls). The statistical significance level was set at $p<0.05$ (two-tailed).

\section{Results}

53 The effective coverage of 4ANC visits, institutional delivery, and PNC visit was $52 \%$, $33 \%$ and $23 \%$, respectively. Women with advantaged ethnicity were more likely and women living in province six, who speak the Maithili language, who had high birth order ( $\geq 4$ ) were less likely to have good EC of MNH visits compared to their reference categories. Women who had access to a bank account, completed at least 4ANC visits or had caesarian-section delivery were more likely to have good EC of $\mathrm{MNH}$ visits. Women who perceived problem if not seen by female providers had poor $\mathrm{EC}$ of $\mathrm{MNH}$ visits compared to their reference counterpart.

\section{Conclusions}

Women with ethnic and social disadvantages and remote areas had poor EC of $\mathrm{MNH}$ visits. Continuous monitoring of $\mathrm{EC}$ of $\mathrm{MNH}$ visits is vital, especially among women with markers of disadvantages. Policies and programs should focus on increasing the uptake of essential MNH interventions, especially among women with social disadvantages and those living in remote areas. 
68 Keywords: Effective coverage, health facility, maternal and newborn health, determinants, Nepal

\section{Introduction}

Globally, maternal and neonatal mortality have declined over the last few decades; however, most of these deaths are concentrated in the low- and lower-middleincome (LMICs) countries within Sub-Saharan Africa and South and South-East Asia [1]. Most maternal and newborn deaths can be prevented by improved access to and quality of essential antenatal, intrapartum, and postnatal interventions. According to the World Health Organization (WHO), every pregnant woman (and newborn) should receive these essential interventions [2, 3]. During pregnancy, women should receive at least four antenatal care (ANC) visits encompassing antenatal interventions (e.g., iron supplementation, tetanus toxoid immunisation) and be screened for high-risk pregnancy [4]. Intrapartum interventions include childbirth assisted by skilled birth attendants; women and newborn should receive intrapartum and immediate newborn care interventions [5]. Postnatal interventions cover the examination of mother and their babies for any infections, advice for hygiene and sanitation, advice for nutrition and family planning during the first week of childbirth [6]. Every woman (and newborns) should complete at least three postnatal care (PNC) visits within the first week of childbirth [7]. The composite coverage of those technical interventions and procedures can be described as the effective coverage (EC) of health services [8]. The EC of health services account for multiple dimensions of quality of health care, including frequency and adequacy of services provided by skilled health workers [9], and service uptakes (of essential interventions) at HFs [3, 10].

Despite increased access to routine maternal and newborn ( $\mathrm{MNH}$ ) visits in many LMICs [11, 12], the reduction of the Maternal Mortality Ratio (MMR) and the Neonatal Mortality Rate (NMR) is slow [13]. Poor uptake of essential interventions during routine $\mathrm{MNH}$ visits have contributed to the stagnant or slow rate of reduction of NMR and MMR [3]. Only reaching at HFs, however, does not guarantee that women receive all the recommended interventions [14]. Programs and research need to also examine the actual receipt of essential $\mathrm{MNH}$ interventions and patterns and determinants of EC of health services including MNH services $[15,16]$. 
Measuring EC requires information about what happens at HF after visits, and can provide insights into the quality of health services [17, 18]. Estimation of EC incorporates the population in need of health services, the proportion of HFs contact for services, and the composite coverage of uptake of essential $\mathrm{MNH}$ interventions at the HFs and reflects the performance of health systems [2, 19]. The EC of health services, therefore, provides a proxy measure of the quality of health services [20, 21] and is being given a high priority in policies and programs, especially in reproductive, maternal and child health programs $[8,22,23]$.

Nepal has a high MMR (259 per 100,000 live births) and NMR (21 per 1000 live births) within South Asia [24]. Further, while significant progress has been made, the rate of reduction has slowed substantially compared to the rates of increases in $\mathrm{MNH}$ visits over the past two decades in Nepal. For instance, from 2006 to 2016, institutional delivery increased from $18 \%$ to $59 \%$, while MMR decreased from 281 to 259 in the same period [25]. Evidence suggests that high death rates among disadvantaged groups who usually have low coverage of routine MNH visits [25]. The slow progress in women and newborns' survival can be explained by either disadvantaged women having poor access to recommended $\mathrm{MNH}$ interventions or the health system is inefficient in providing essential $\mathrm{MNH}$ interventions.

117 In the current health policy document, Nepal has prioritised quality of care as the health system's overarching principle, within the Nepal health sector strategy (NHSS) (2015-2020) [26], the national health policy 2019 [27] and the Nepal Safe Motherhood and Newborn Health Roadmap 2030 [28] emphasizing the universal quality of health services for achieving Sustainable Development Goal 3(SDG3), including MNH services [29]. The current system, however, lacks a healthcare quality monitoring mechanism. Neither the routine health information system such as health management information system (HMIS) [30] nor do any strategic documents describe the measurement of EC of health services, including for $\mathrm{MNH}$ [31, 32]. While studies have examined contact coverage of routine MNH visits [33, 34] and 127 perceived quality of care $[35,36]$, little is known evidence is published in the EC of 128 routine $\mathrm{MNH}$ visits [37]. This study examined about the patterns and determinants of 129 EC of routine MNH visits. This study begins to address this gap findings and may 130 inform programs and policies to target women groups with a high burden of maternal 
and newborn mortalities but with poor access to quality MNH services in Nepal and similar settings.

\section{Methods}

\section{Data sources and sampling design}

The NDHS 2016 data were used for this study, extracted data of individual women record from the NDHS. The NDHS 2016 is a nationally representative crosssectional survey conducted to assess the health services performance, especially health status of reproductive, newborn, child health and nutrition [25].

A more detailed sampling method is described in the NDHS 2016 report [25]. In brief, the NDHS 2016 identified rural and urban sampling strata from seven provinces producing 14 strata. The survey adopted a two-stage sampling design. The first stage involved a systematic selection of 383 clusters with probability proportional to size from urban and rural strata. The second stage consisted of selecting 30 households per cluster through a systematic sampling from a selected household. Of selected 11,203 households but 11,040 responded to the survey. From those households, of 13,089 women age 15-49 years identified for interviews, 12,862 responded (response rate of 98\%). Among them, 3,998 women had a live birth five years preceding the survey. This study included 1,978 women aged 15-49 years who had a live birth in the two years preceding the survey as this sample included information on pregnancy, childbirth, and postnatal care interventions.

\section{Conceptual framework of the study}

Based on the review of previous conceptual frameworks [38-40], a conceptual framework was developed for this study (Figure 1). This conceptual framework comprises inputs that include several determinants, their contexts and mechanisms at system, institutional and individual level. These contexts and mechanisms can produce the output of effective uptake of $\mathrm{MNH}$ interventions. Improved output as EC of $\mathrm{MNH}$ visits may lead to the survival of mothers and newborns, economic benefit, and confidence in the system. Inputs are broadly categorised into three domains: structural, intermediary, and health system. Structural factors cover all basic factors (e.g., wealth status, ethnicity, gender) that can influence the intermediary and health system factors. Intermediary factors are non-health sector factors, which generally 
162 affect the conditions of health via influencing the family/community contexts (living 163 and working conditions) and individual characteristics. Health system variables

164 include several variables that involve in the provision and delivery of quality health 165 services.

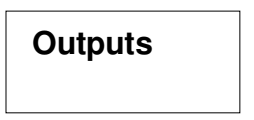

Impacts

\section{Structural domain:}

Governance, macroeconomic and social policies, culture and societal values, individuals' characteristics (e.g. social class, gender, education, occupation, income, religion, ethnicity)

\section{Intermediary domain:}

Sectors that influence conditions of health, daily lives, geography

transportation, language, media exposure and awareness on health, individuals' behavioural, biological and psychological characteristics

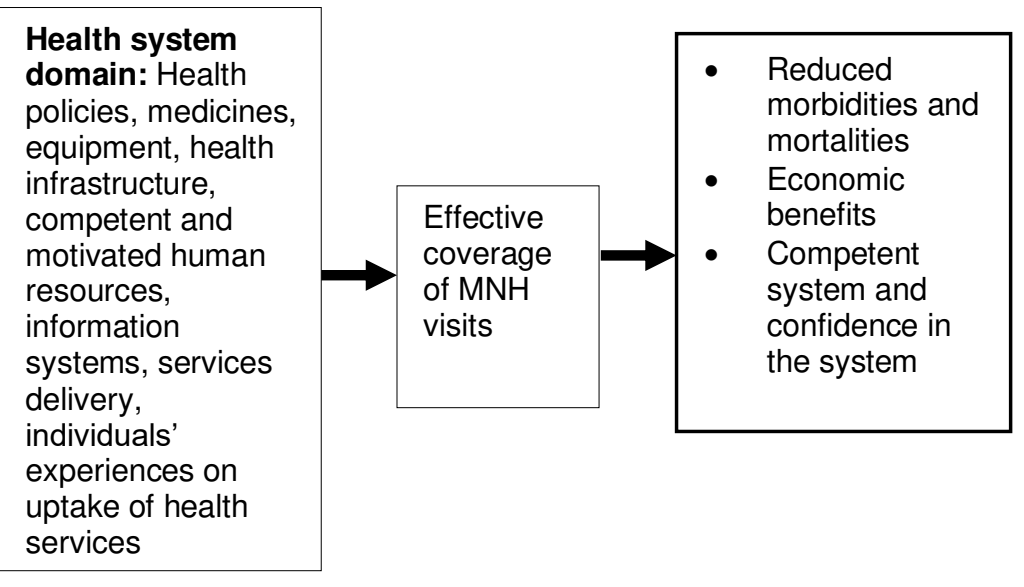

176 Figure 1 A conceptual framework adapted and modified from the WHO's Commission

177 on Social Determinants of Health [41].

\section{Study variables}

180 Independent variables included characteristics of women and their healthcare 181 experience (Supplementary Table S1). Based on available information in the NDHS

1822016 data, and as guided by the conceptual framework (Figure 1). The variables

183 under the structural domain were ethnicity, wealth status, education, religion,

184 maternal occupation, perceived violence, decision-making for at least one of three

185 areas (healthcare, purchasing, and movement) and sex of household head. In

186 addition, independent variables under the intermediary domain were the age of

187 mothers, first language, residence, provinces, region, birth order, sex of the child,

188 access to a bank account, media exposure, distance to health facilities as perceived 
problem, and intended birth of the last child. Health system factors included the

190 (perceived) problem of not having female healthcare providers, awareness of health mothers' groups, mode of delivery, and EC of 4 ANC visits, and EC of institutional delivery.

Taking reference from past studies [33, 34, 42, 43], ethnicity, education, wealth status were further defined for this study. The Government of Nepal has categorised 123 ethnicities into six broader categories: i) Dalits (untouchable), ii) disadvantaged indigenous, iii) disadvantaged non-Dalit Terai caste groups, iv) religious minorities (Muslims), v) relatively advantaged indigenous, and vi) upper-caste groups. These broader ethnic groups were merged into two groups according to their comparative privileges: disadvantaged ethnicities (includes Dalit, Muslims, and non-Dalit Terai caste, disadvantaged Janajatis) and advantaged ethnicities (includes Brahmin or Chhetri, advantaged Janajatis). Maternal education was categorised as illiterate 202 (who cannot read and write), and primary (who can read and write and up to grate 203 8), and secondary and higher (who have grade 8 and higher-level education). In the NDHS 2016, wealth quintiles were constructed using principal component analysis 205 (PCA) based on more than 40 -asset items being owned by households. The lowest two quintiles were merged as lower wealth status (lower 40\%), and the upper three quintiles were combined as upper wealth status (upper 60\%) (Table 1).

Three outcome variables with binary categories, collectively called routine $\mathrm{MNH}$ 209 visits included in this study, were i) EC of $4 A N C$ visit; ii) EC of institutional delivery; iii) EC of PNC visit. For each MNH visit if score $>0$ and $\leq 0.8=0$ (poor coverage); and 211 if score $>0.8=1$ (good coverage). The binary outcomes of each variable were coded as: 4ANC visits: $1=$ good coverage; $0=$ poor coverage; Institutional delivery: $1=$ good coverage; $0=$ poor coverage; PNC visit: $1=$ good coverage; $0=$ poor coverage.

214

\section{Measurement of EC of routine MNH visits}

216 Based on the information available in NDHS 2016, EC scores were calculated for 217 those women who attended the health facilities for routine MNH visits. For EC of any $218 \mathrm{MNH}$ visit, women should receive sets of interventions by skilled providers, timely, 219 adequate and appropriate content of care at the pregnancy [5], childbirth [44] and the postnatal period [45]. We identified selected MNH interventions (4ANC:16 items; 
221 institutional delivery: 8 items; and PNC visits for mothers and newborns: 11 items)

222 (Supplementary Table S2). Then we calculated the EC score of 4ANC visits,

223 institutional delivery, and PNC visits. Scores (>0 to 1) were calculated for each $\mathrm{MNH}$

224 visit; if women received ten interventions in ANC visits, then the coverage score

225 would be $0.625(=10 / 16)$ [23]. For women who completed 4ANC visits, delivered at a

226 health institution, or made a PNC visit, the coverage score would be $>0$ to 1 of each

$227 \mathrm{MNH}$ visit [2]. Based on these woman-specific coverage scores of each $\mathrm{MNH}$ visit,

228 population-level $\mathrm{EC}$ was calculated using formula $\mathrm{EC}=\mathrm{Q} \times \mathrm{U} \mid \mathrm{N}$ [46]. In this formula,

229 EC refers to effective coverage of $\mathrm{MNH}$ visit at the national level, $\mathrm{Q}$ relates to the

230 average quality score of all interventions of particular MNH visit (e.g.4ANC visits),

231 and $\mathrm{U}$ refers to the utilisation of $\mathrm{MNH}$ visit (the contact coverage of the $\mathrm{MNH}$ visit),

232 and $\mathrm{N}$ is the number of population of need $[2,23]$.

233

234 For the regression analysis to identify determinants of EC of $\mathrm{MNH}$ visits, coverage

235 scores were dichotomised, taking woman-specific score (of respective MNH visit).

236 Although there are no gold standards of cut-off points for categorisation of poor or

237 good effective coverage, this study took reference cut-off point of 0.80 to a previous

238 study undertaken in Kenya [47] and Nepal [48]. Then scores were dichotomised into

239 poor EC (if scores $>0$ and $\leq 0.8$ ) and good EC (if scores $>0.8$ ) to identify the

240 determinants of good EC of MNH visits. For each $\mathrm{MNH}$ visit, EC scores were

241 dichotomised into poor EC (if score $>0$ and $\leq 0.8$ ) and good EC (if score $>0.8$ ), that is

242 i) EC of $4 A N C$ visits, ii) EC of institutional delivery, and iii) EC of at least one PNC

243 visit for mothers and newborns within 48 hours of childbirth.

244

245 Statistical analyses

246 All the analyses are adjusted for sampling weights available in the dataset to account

247 for two-stage cluster sampling used in the NDHS 2016 survey (primary sampling

248 unit=383; stratification (seven provinces with rural/urban dichotomy; strata=14);

249 survey weights (probability weight =sample weight/1,000,000) [25]. Thus, results are

250 representative at the national as well as strata levels. Statistical significance level

251 was set $p<0.05$ (two-tailed) to identify the determinants associated with the outcome

252 variable. All reported estimates were weighted (unless otherwise indicated).

253 Binomial logistic regression analyses were conducted to identify determinants of EC 
254 of $\mathrm{MNH}$ visits. Three independent multivariable logistic regression analyses were conducted for each outcome variable, for example, Model I for EC of 4ANC visits; Model II for EC of institutional delivery; Model III for EC of the first PNC visit for mothers and newborns within 48 hours of childbirth. The extent of inequities was reported in terms of odds ratios (OR) with $95 \%$ confidence intervals (Cls). Before running final regression model, multicollinearity was checked: excluded independent variables having variation inflation factors (VIF) $\geq 3$ in the multivariable regression analyses [49]. Backward elimination multivariable logistic regression analyses were conducted [50]. For which, firstly, a full multivariable regression model was run, and then estimated $p$-values for each independent variable and the insignificant variable were identified. This procedure was repeated until no insignificant independent variable was left at $p<0.2$ [51]. The adjusted odds ratios $(\mathrm{aOR})$ with $95 \% \mathrm{Cls}$ for all independent variables retaining $p<0.05$ were reported. The goodness of fit tests was conducted using the Hosmer Lemeshow test (non-significant results $(p>0.05)$ indicated an adequate fit) [52]. All analyses were conducted using the survey command function and considering the clustering effect in Stata 14.0 (Stata Corp, 2015).

\section{Results}

\section{Descriptive characteristics of women}

273 Table 1 shows the background characteristics of the women included in the analysis.

274 Among 1,978 women, 42\% were from households in the lowest two wealth quintiles.

275 More than two-thirds (69\%) of women were from disadvantaged ethnic groups,

276 mostly Madhesi, Janajatis and Dalits. Nearly two in five women (42\%) were native

277 Nepali speakers (the national language). Male household head characterised more 278 than two-thirds $(73 \%)$ of the households. More than half $(55 \%)$ of women were from 279 the Terai (Plain) Region. One in four women (26\%) were from province two, whereas 280 one in twenty women (6\%) were from province six. About half $(46 \%)$ of women were 281 from urban areas. Two-thirds (67\%) of women had no decision-making authority (or 282 empowerment) in relation to access in health-seeking, buying something (financial 283 empowerment) or meeting with relatives (movement authority). Nearly one-third $284(29 \%)$ of women reported any kind of perceived violence (e.g., beating when food 285 burnt or beating if women went out without asking husband). In total, four in five 286 $(79.7 \%)$ women were aged $20-34$ years, and approximately $69 \%$ of women did not 
287 have a bank account. Three in five women perceived distance to a health facility was 288 a challenge when accessing health services. Further, nearly $72 \%$ of women 289 perceived it as challenging to access care when there was no available female 290 healthcare worker. In addition, over two-thirds (68\%) of women had no awareness of 291 the availability of a health mothers' group in their community. One in ten mothers 292 delivered babies via C-section (Table 1).

293 Table 1: Characteristics of women who had a live birth in the two years preceding the 294 survey in Nepal, NDHS $2016(\mathrm{~N}=1978)$

\begin{tabular}{|c|c|c|}
\hline Determinants & Categories & Frequency, n (\%) \\
\hline \multicolumn{3}{|l|}{ Structural } \\
\hline \multirow[t]{2}{*}{ Wealth status } & Lower $(40 \%)$ & $832(42.0)$ \\
\hline & Upper $(60 \%)$ & $1146(58.0)$ \\
\hline \multirow[t]{2}{*}{ Ethnicity } & Disadvantaged & $1374(69.5)$ \\
\hline & Advantaged & $604(30.5)$ \\
\hline \multirow[t]{2}{*}{ Religion } & Others & $306(15.5)$ \\
\hline & Hindu & $1672(84.5)$ \\
\hline \multirow[t]{3}{*}{ Maternal education } & No & $570(28.8)$ \\
\hline & Primary & $391(19.8)$ \\
\hline & Secondary or higher & $1016(51.4)$ \\
\hline \multirow[t]{3}{*}{ Maternal occupation } & Not working & $928(46.9)$ \\
\hline & Agriculture & $824(41.6)$ \\
\hline & Working paid & $227(11.5)$ \\
\hline \multirow[t]{2}{*}{ Perceived violence } & No & $1397(70.6)$ \\
\hline & Yes & $581(29.4)$ \\
\hline \multirow[t]{2}{*}{ Decision-making authority } & No & $1324(66.9)$ \\
\hline & Yes & $654(33.0)$ \\
\hline \multirow[t]{2}{*}{ Household head } & Male & $1438(72.7)$ \\
\hline & Female & $540(27.3)$ \\
\hline \multicolumn{3}{|l|}{ Intermediary } \\
\hline \multirow[t]{4}{*}{ Language } & Nepali & $839(42.4)$ \\
\hline & Maithili & $360(18.2)$ \\
\hline & Bhojpuri & $267(13.5)$ \\
\hline & Others & $512(25.9)$ \\
\hline \multirow[t]{2}{*}{ Residence } & Urban & $1062(53.7)$ \\
\hline & Rural & $916(46.3)$ \\
\hline \multirow[t]{7}{*}{ Provinces } & One & $338(17.1)$ \\
\hline & Two & $513(25.9)$ \\
\hline & Three & $312(15.8)$ \\
\hline & Four & $164(8.3)$ \\
\hline & Five & $364(18.4)$ \\
\hline & Six & $121(6.1)$ \\
\hline & Seven & $166(8.4)$ \\
\hline \multirow[t]{3}{*}{ Region } & Mountain & $131(6.6)$ \\
\hline & Hills & $760(38.4)$ \\
\hline & Terai & $1087(55.0)$ \\
\hline \multirow[t]{3}{*}{ Maternal age (in years) } & $15-19$ & 291 (14.7) \\
\hline & $20-34$ & $1570(79.7)$ \\
\hline & $35+$ & $106(5.3)$ \\
\hline \multirow[t]{2}{*}{ Birth order (index child) } & $<4$ & $1678(84.8)$ \\
\hline & $\geq 4$ & $300(15.2)$ \\
\hline \multirow[t]{2}{*}{ Sex of index child } & Male & $1063(53.7)$ \\
\hline & Female & $915(46.2)$ \\
\hline \multirow[t]{2}{*}{ Access to bank account } & No & $1367(69.1)$ \\
\hline & Yes & $611(30.9)$ \\
\hline
\end{tabular}




\begin{tabular}{l|l|r}
\hline Determinants & Categories & Frequency, $\mathbf{n}(\%)$ \\
\hline Media exposure & No & $911(46.0)$ \\
\hline Last birth (index child) & Yes & $1067(54.0)$ \\
\hline $\begin{array}{l}\text { Distance to health facilities as a perceived } \\
\text { problem }\end{array}$ & Unwanted & $418(21.1)$ \\
\hline & Wanted & $1560(78.8)$ \\
\hline Health system & No problem & $763(38.6)$ \\
\hline Perceived problem not having female providers & Big problem & No problem \\
\hline & Big problem & $1213(61.4)$ \\
\hline $\begin{array}{l}\text { Awareness on health mothers' group in the } \\
\text { community }\end{array}$ & No & $562(28.4)$ \\
\hline & & $1416(71.6)$ \\
\hline Mode of delivery & Yes & $1340(67.7)$ \\
\hline EC of 4ANC visits (n=1401) & Normal (veginal) & $638(32.3)$ \\
\hline & C-section & $1780(90.0)$ \\
\hline EC of institutional delivery $(n=1270)$ & Poor coverage & $198(10.0)$ \\
\hline EC of first PNC visit $(n=999)$ & Good coverage & $504(36.0)$ \\
\hline & Poor coverage & $897(64.0)$ \\
\hline & Good coverage & $724(57.0)$ \\
\hline & Poor coverage & $546(43.0)$ \\
\hline & Good coverage & $335(33.5)$ \\
\hline
\end{tabular}

296 Among 1,978 women, a total of $71 \%(n=1,401)$ women received four ANC visits;

$29764 \%(n=1,270)$ women delivered babies at health facilities assisted by skilled health

298 personnel, and $51 \%(n=999)$ received at least one PNC visit for mothers and their

299 newborns within 48 hours of childbirth. The average uptake of the interventions

300 (quality score) of $4 \mathrm{ANC}$ visits, institutional delivery and first PNC visit was $0.73,0.51$,

301 and 0.46 , respectively. The population of need $100 \%$ of those who were gone

302 through pregnancy, childbirth, and postnatal period. The EC of 4ANC visits,

303 institutional delivery and PNC visit was $52 \%, 33 \%$ and $23 \%$, respectively

304 (Supplementary Table S2).

Table 2 shows the descriptive characteristics of the EC of routine MNH visits. Among 1,401 women who completed 4ANC visits, $64 \%$ received good EC of $4 A N C$ visits.

307 Women were more likely to receive good EC of 4ANC visits if they were a Nepali native speaker (76\%), belonged to an advantaged ethnicity (80\%), had a job $(76 \%)$, lived in province seven $(79 \%)$, had access to a bank account $(77 \%)$, or perceived a problem of not having female provider present $(80 \%)$, compared to their reference

311 counterparts. Similarly, among women who delivered at health institutions $(N=1270)$,

$31233 \%$ had good EC of institutional delivery. Women who were Nepali speakers (47\%),

313 belonged to an advantaged ethnicity $(47 \%)$, lived in province four $(51 \%)$ or a hill 314 region (47\%), or who had a history of uptake of 4 ANC $(51 \%)$ visits had good EC of institutional delivery compared to their reference counterparts. In addition, two-thirds 
$316(66.5 \%, \mathrm{~N}=999)$ of women who accessed PNC services received good EC of PNC 317 visit. Women received good EC of their PNC visit if they had higher wealth status 318 (69\%), higher (high school and above) maternal education $(70 \%)$ or a job $(77 \%)$, or 319 lived in province four ( $76 \%$ ), had access to a bank account $(72 \%)$, or delivered via 320 caesarean-section (87\%) compared to their reference counterparts. 
Table 2: Good EC of routine MNH visits in Nepal, NDHS 2016

\begin{tabular}{|c|c|c|c|c|c|c|c|c|c|c|}
\hline \multirow[t]{2}{*}{ Determinants } & \multirow[t]{2}{*}{ Categories } & \multicolumn{3}{|c|}{ 4ANC visits ( $N=1401)$} & \multicolumn{3}{|c|}{ Institutional delivery ( $\mathrm{N}=1270)$} & \multicolumn{3}{|c|}{ PNC visit (N=999) } \\
\hline & & $\mathrm{n}$ & $\begin{array}{l}\text { \% of } \\
\text { good EC }\end{array}$ & $\mathrm{p}$ & $\mathrm{n}$ & $\begin{array}{l}\% \text { of good } \\
\text { EC }\end{array}$ & $\mathrm{p}$ & $\mathrm{n}$ & $\begin{array}{l}\% \text { of } \\
\text { good EC }\end{array}$ & $p$ \\
\hline \multicolumn{11}{|l|}{ Structural } \\
\hline \multirow[t]{2}{*}{ Wealth status } & Lower $(40 \%)$ & 539 & 61.5 & 0.242 & 405 & 42.1 & 0.692 & 329 & 60.8 & 0.035 \\
\hline & Upper $(60 \%)$ & 862 & 65.6 & & 865 & 43.4 & & 670 & 69.3 & \\
\hline \multirow[t]{2}{*}{ Ethnicity } & Disadvantaged & 903 & 55.2 & $<0.001$ & 819 & 41.0 & 0.078 & 615 & 64.0 & 0.110 \\
\hline & Advantaged & 498 & 80.1 & & 451 & 46.6 & & 384 & 70.5 & \\
\hline \multirow[t]{2}{*}{ Religion } & Others & 186 & 59.3 & 0.333 & 193 & 45.2 & 0.591 & 145 & 66.4 & 0.990 \\
\hline & Hindu & 1,215 & 64.8 & & 1,076 & 42.6 & & 854 & 66.5 & \\
\hline \multirow[t]{3}{*}{ Education } & No & 305 & 47.9 & $<0.001$ & 270 & 38.5 & 0.278 & 207 & 60.9 & 0.060 \\
\hline & Primary & 249 & 58.7 & & 208 & 40.5 & & 160 & 61.6 & \\
\hline & Secondary /higher & 847 & 71.4 & & 792 & 45.2 & & 632 & 69.6 & \\
\hline \multirow[t]{3}{*}{ Occupation } & Not working & 622 & 58.8 & 0.002 & 636 & 41.5 & 0.082 & 467 & 63.9 & 0.060 \\
\hline & Agriculture & 596 & 65.7 & & 460 & 41.6 & & 387 & 65.6 & \\
\hline & Working paid & 183 & 76.4 & & 174 & 51.9 & & 146 & 77.1 & \\
\hline \multirow[t]{2}{*}{ Perceived violence } & No & 1,009 & 65.0 & 0.352 & 916 & 43.2 & 0.861 & 741 & 67.1 & 0.541 \\
\hline & Yes & 393 & 61.6 & & 354 & 42.6 & & 258 & 64.7 & \\
\hline \multirow[t]{2}{*}{ Decision-making authority } & No & 915 & 60.5 & 0.003 & 830 & 39.7 & 0.013 & 645 & 65.2 & 0.342 \\
\hline & Yes & 486 & 70.7 & & 439 & 49.3 & & 354 & 68.9 & \\
\hline \multirow[t]{2}{*}{ Household head } & Male & 1,002 & 62.6 & 0.168 & 908 & 42.1 & 0.375 & 700 & 65.8 & 0.565 \\
\hline & Female & 400 & 67.5 & & 361 & 45.3 & & 299 & 68.2 & \\
\hline \multicolumn{11}{|l|}{ Intermediary } \\
\hline \multirow[t]{4}{*}{ Lanquage } & Nepali & 673 & 76.2 & $<0.001$ & 589 & 47.2 & 0.073 & 484 & 68.1 & 0.008 \\
\hline & Maithili & 244 & 31.7 & & 204 & 37.2 & & 147 & 56.1 & \\
\hline & Bhoipuri & 121 & 55.5 & & 141 & 36.5 & & 90 & 55.4 & \\
\hline & Others & 363 & 65.9 & & 336 & 41.9 & & 278 & 72.7 & \\
\hline \multirow[t]{2}{*}{ Residence } & Urban & 802 & 68.4 & 0.009 & 781 & 43.9 & 0.449 & 611 & 67.3 & 0.597 \\
\hline & Rural & 599 & 58.1 & & 489 & 41.6 & & 388 & 65.3 & \\
\hline \multirow{7}{*}{ Provinces } & One & 266 & 59.7 & $<0.001$ & 223 & 41.0 & 0.037 & 184 & 75.6 & 0.001 \\
\hline & Two & 298 & 36.9 & & 280 & 36.8 & & 196 & 53.9 & \\
\hline & Three & 236 & 76.4 & & 226 & 50.6 & & 196 & 70.4 & \\
\hline & Four & 124 & 78.1 & & 121 & 50.4 & & 105 & 76.0 & \\
\hline & Five & 272 & 71.9 & & 239 & 46.0 & & 187 & 67.4 & \\
\hline & Six & 66 & 68.7 & & 53 & 37.7 & & 44 & 45.1 & \\
\hline & Seven & 139 & 79.2 & & 128 & 36.2 & & 87 & 64.3 & \\
\hline Region & Mountain & 94 & 62.4 & $<0.001$ & 59 & 30.0 & 0.015 & 60 & 72.5 & 0.019 \\
\hline
\end{tabular}




\begin{tabular}{|c|c|c|c|c|c|c|c|c|c|c|}
\hline \multirow[t]{2}{*}{ Determinants } & \multirow[t]{2}{*}{ Categories } & \multicolumn{3}{|c|}{ 4ANC visits ( $N=1401)$} & \multicolumn{3}{|c|}{ Institutional delivery $(\mathrm{N}=1270)$} & \multicolumn{3}{|c|}{ PNC visit (N=999) } \\
\hline & & $\mathrm{n}$ & $\begin{array}{l}\% \text { of } \\
\text { good EC }\end{array}$ & $\mathrm{p}$ & $\mathrm{n}$ & $\begin{array}{l}\text { \% of good } \\
\text { EC }\end{array}$ & $\mathrm{p}$ & $\mathrm{n}$ & $\begin{array}{l}\% \text { of } \\
\text { good EC }\end{array}$ & $\mathrm{p}$ \\
\hline & Hill & 579 & 74.8 & & 514 & 47.1 & & 434 & 71.5 & \\
\hline & Terai & 728 & 55.7 & & 697 & 41.1 & & 505 & 61.5 & \\
\hline \multirow[t]{3}{*}{ Maternal age (in years) } & $15-19$ & 216 & 54.5 & 0.003 & 206 & 41.2 & 0.322 & 145 & 65.8 & 0.838 \\
\hline & $20-34$ & 1,120 & 66.4 & & 1,007 & 43.9 & & 813 & 66.4 & \\
\hline & $35+$ & 66 & 54.9 & & 57 & 32.3 & & 41 & 71.0 & \\
\hline \multirow[t]{2}{*}{ Birth order (index child) } & $<4$ & 1,260 & 66.0 & $<0.001$ & 1,153 & 44.0 & 0.081 & 903 & 68.4 & 0.001 \\
\hline & $\geq 4$ & 142 & 46.6 & & 117 & 33.4 & & 96 & 48.7 & \\
\hline \multirow[t]{2}{*}{ Child sex (index child) } & Male & 756 & 65.3 & 0.337 & 698 & 44.3 & 0.330 & 563 & 67.3 & 0.631 \\
\hline & Female & 645 & 62.5 & & 572 & 41.3 & & 436 & 65.5 & \\
\hline \multirow[t]{2}{*}{ Access to bank account } & No & 904 & 57.1 & $<0.001$ & 798 & 40.9 & 0.120 & 606 & 63.3 & 0.022 \\
\hline & Yes & 498 & 76.6 & & 472 & 46.5 & & 393 & 71.5 & \\
\hline \multirow[t]{2}{*}{ Media exposure } & No & 546 & 55.6 & $<0.001$ & 463 & 40.6 & 0.184 & 332 & 58.6 & 0.002 \\
\hline & Yes & 855 & 69.4 & & 807 & 44.4 & & 667 & 70.4 & \\
\hline \multirow[t]{2}{*}{ Last birth (index child) } & Unwanted & 252 & 60.1 & 0.229 & 243 & 41.3 & 0.678 & 183 & 68.7 & 0.516 \\
\hline & Wanted & 1,149 & 64.9 & & 1,027 & 43.4 & & 816 & 66.0 & \\
\hline \multirow[t]{2}{*}{ Distance to health facilities } & No problem & 588 & 71.6 & $<0.001$ & 581 & 45.3 & 0.174 & 468 & 70.6 & 0.037 \\
\hline & Big problem & 814 & 58.6 & & 689 & 41.0 & & 531 & 62.9 & \\
\hline \multicolumn{11}{|l|}{ Health system } \\
\hline \multirow{2}{*}{$\begin{array}{l}\text { Perceived problem if not } \\
\text { having female providers }\end{array}$} & No Problem & 438 & 79.6 & $<0.001$ & 419 & 47.2 & 0.057 & 349 & 73.8 & 0.002 \\
\hline & Bia problem & 963 & 57.0 & & 851 & 40.9 & & 650 & 62.6 & \\
\hline \multirow{2}{*}{$\begin{array}{l}\text { Awareness on health } \\
\text { mothers' group }\end{array}$} & No & 904 & 59.9 & $<0.001$ & 844 & 42.4 & 0.562 & 635 & 67.0 & 0.701 \\
\hline & Yes & 497 & 71.6 & & 426 & 44.2 & & 364 & 65.6 & \\
\hline \multirow[t]{2}{*}{ C-section delivery } & No & 1,235 & 62.8 & 0.023 & 1,072 & 44.7 & 0.016 & 834 & 62.4 & $<0.001$ \\
\hline & Yes & 166 & 73.2 & & 198 & 34.0 & & 165 & 86.9 & \\
\hline \multirow[t]{2}{*}{ EC of $4 A N C$ visits } & Poor coverage & & & & 547 & 33.2 & $<0.00$ & 383 & 56.9 & $<0.001$ \\
\hline & Good & & & & 723 & 50.4 & & 615 & 72.5 & \\
\hline \multirow[t]{2}{*}{ EC of institutional delivery } & Poor & & & & & & & 541 & 64.0 & 0.111 \\
\hline & Good & & & & & & & 457 & 69.4 & \\
\hline
\end{tabular}




\section{Determinants of good EC of routine MNH visits}

In the bivariable logistic analysis, 16 (of 19) variables were significantly associated with EC of 4ANC visits. Similarly, six (of 23) variables were significantly associated with good EC of institutional delivery. Total 12 (of 20) variables were significantly associated with good EC of PNC visit (Supplementary Table S3).

In the multivariate logistic regression analysis (Model I) for determinants of EC of $4 A N C$ visits, six variables were significantly associated with good EC of 4ANC visits. Maithili speakers had lower odds (aOR $=0.42 ; 95 \% \mathrm{Cl}: 0.20,0.88)$ of good EC of 4ANC visits. There was good EC of 4ANC visits if women resided in province four $(\mathrm{aOR}=1.69 ; 95 \% \mathrm{Cl}: 1.02,2.79)$ or seven $(\mathrm{aOR}=2.41 ; 95 \% \mathrm{Cl}: 1.46,3.97)$, belonged to an advantaged ethnicity $(\mathrm{aOR}=1.68 ; 95 \% \mathrm{Cl}: 1.16,2.43)$, and had a bank account $(\mathrm{aOR}=1.48 ; 95 \% \mathrm{Cl}: 1.08,2.03)$ compared to their reference counterparts. Women with higher birth order $(\geq 4)(\mathrm{aOR}=0.54 ; 95 \% \mathrm{Cl}: 0.35,0.85)$, and the perceived problem of not having female providers $(\mathrm{aOR}=0.47 ; 95 \% \mathrm{Cl}: 0.33,0.67)$ were found to have a significant negative association with the uptake of good EC of 4ANC visits (Table 3).

In the multivariable analysis (Model II for determinants of EC of institutional delivery), two variables (mode of delivery and continuity of 4ANC visits) were significantly associated with EC of institutional delivery. Women who had delivery via caesareansection had lower odds (aOR=0.54; 95\% Cl: $0.37,0.80)$ of $E C$ of institutional delivery services compared to women who had a normal delivery. Women with at least 4ANC visits during their pregnancy had higher odds (aOR=1.78;95\% $\mathrm{Cl}: 1.33,2.38)$ of good EC of institutional delivery compared to women who did not (Table 3).

In the multivariable analysis (Model III for determinants of EC of PNC visit), six variables were significantly associated with EC of PNC visit. Nepali speaker women (aOR=0.65; 95\% Cl: 0.43, 0.99), women from province six (aOR=0.34; 95\% Cl: 0.18, $0.64)$ and province seven $(\mathrm{aOR}=0.56 ; 95 \% \mathrm{Cl}: 0.31,0.99)$, the perceived problem if not having female providers $(\mathrm{aOR}=0.67 ; 95 \% \mathrm{Cl}: 0.47,0.96)$, or higher birth order $(\geq$ 4) $(\mathrm{aOR}=0.52 ; 95 \% \mathrm{Cl}: 0.29,0.93)$, had a significant negative association with $\mathrm{EC}$ of PNC visit. C-section (aOR=4.20; 95\% Cl: 2.29, 7.68), and $E C$ of $4 A N C$ visits $(\mathrm{aOR}=1.69 ; 95 \% \mathrm{Cl}: 1.18,2.43)$ had a significant positive association with good $\mathrm{EC}$ of PNC visit (Table 3). 
Table 3: Multivariable logistic regression for factors associated with good EC of routine $\mathrm{MNH}$ visits in Nepal, $2016(\mathrm{~N}=1,978)$

\begin{tabular}{|c|c|c|c|c|}
\hline Determinants & Categories & $\begin{array}{l}\text { Model I\# } \\
\text { aOR }(95 \% \mathrm{Cl})\end{array}$ & $\begin{array}{l}\text { Model II } \\
\text { aOR }(95 \% \mathrm{Cl})\end{array}$ & $\begin{array}{l}\text { Model III } \\
\text { aOR }(95 \% \mathrm{Cl})\end{array}$ \\
\hline \multicolumn{5}{|l|}{ Structural } \\
\hline \multirow[t]{2}{*}{ Ethnicity } & $\begin{array}{l}\text { Disadvantage } \\
\text { d }\end{array}$ & 1.00 & & \\
\hline & Advantaged & $1.68(1.16,2.43)^{* *}$ & & \\
\hline \multicolumn{5}{|l|}{ Intermediary } \\
\hline \multirow[t]{4}{*}{ Languages } & Nepali & 1.00 & & $0.65^{\star}(0.43,0.99)$ \\
\hline & Maithili & $0.42(0.20,0.88)^{*}$ & & $0.48(0.22,1.09)$ \\
\hline & Bhojpuri & $1.01(0.48,2.14)$ & & $0.59(0.29,1.22)$ \\
\hline & Others & $0.82(0.53,1.25)$ & & 1.00 \\
\hline \multirow[t]{7}{*}{ Provinces } & One & 1.00 & & 1.00 \\
\hline & Two & $0.74(0.37,1.49)$ & & $0.73(0.37,1.46)$ \\
\hline & Three & $1.65(0.97,2.80)$ & & $0.65(0.34,1.23)$ \\
\hline & Four & $1.69(1.02,2.79)^{*}$ & & $0.92(0.47,1.81)$ \\
\hline & Five & $1.47(0.88,2.46)$ & & $0.72(0.44,1.18)$ \\
\hline & Six & $1.37(0.77,2.43)$ & & $\underset{* \star * *}{0.34}(0.18,0.64)$ \\
\hline & Seven & $2.41(1.46,3.97)^{* * *}$ & & $0.56(0.31,0.99)$ * \\
\hline \multirow[t]{2}{*}{ Birth order (index child) } & $<4$ & 1.00 & & 1.00 \\
\hline & $\geq 4$ & $0.54(0.35,0.85)^{\star *}$ & & $0.52(0.29,0.93)^{*}$ \\
\hline \multirow[t]{2}{*}{$\begin{array}{l}\text { Access to a bank } \\
\text { account }\end{array}$} & No & 1.00 & & \\
\hline & Yes & $1.48(1.08,2.03)^{*}$ & & \\
\hline \multicolumn{5}{|l|}{ Health system } \\
\hline \multirow{2}{*}{$\begin{array}{l}\text { Perceived problem not } \\
\text { having female } \\
\text { providers }\end{array}$} & No problem & 1.00 & & 1.00 \\
\hline & Big problem & $0.47(0.33,0.67)^{* * *}$ & & $0.67(0.47,0.96)^{*}$ \\
\hline \multirow[t]{2}{*}{ Mode of delivery } & C-section & & $0.54(0.37,0.80)$ & $4.20(2.29,7.68)$ \\
\hline & Normal & & 1.00 & 1.00 \\
\hline \multirow[t]{2}{*}{ EC of $4 A N C$ visits } & Poor & & 1.00 & 1.00 \\
\hline & Good & & $\underbrace{1.78}_{* * *}(1.33,2.38)$ & $1.69(1.18,2.43)$ \\
\hline
\end{tabular}

Significance at ${ }^{* * *} p<0.001,{ }^{* *} p<0.01,{ }^{*} p<0.05$. EC=effective coverage. Shaded cells: Variables not included in the analysis. Variables that had $p<0.2$ included in the final model.

\#These are separate models adjusting for covariates listed in the respective column.

Model I: outcome variable: good EC of 4ANC visits. Independent variables: wealth status, language, ethnicity, religion, maternal education, maternal occupation, perceived violence, household head, residence, province, maternal age, child sex, access to a bank account, media exposure, index child, empowerment, distance to HFs, the perceived problem of not having female providers, awareness on health mothers' group, c-section delivery.

Model II: outcome variable: good EC of institutional delivery. Independent variables: all variables model I plus the EC of $4 A N C$ visits.

Model III: outcome variable: Good EC of the first PNC visit. Independent variables: variables of model I plus the EC of $4 A N C$ visit, and EC of institutional delivery.

Goodness of fit test (Hosmer Lemeshow test) for Model I $(p=0.575)$, Model $2(p=0.879)$, and Model III $(p=0.493)$. These figures show that our models are the best fit. P-values obtained by Fisher exact test. HMG: health mothers' group. EC= effective coverage, ANC: antenatal care, PNC: postnatal care. 


\section{Discussion}

\section{Summary of the findings}

The effective coverage of 4ANC visits, institutional delivery, and PNC visit was $52 \%$, $33 \%$ and $23 \%$, respectively. These findings provide a baseline for the future estimation of the quality of MNH services in Nepal. Women with disadvantaged ethnicity or those from province six, speaking Maithili as the first language, and those who had high birth order $(\geq 4)$ had lower odds of EC of MNH visits. Women who had access to a bank account, or women who had C-section delivery had higher odds of good EC of MNH visits. Women who perceived problem if not seen by female providers had poor EC of MNH visits compared to who did not care about the gender of health care providers.

\section{EC of routine MNH visits and determinants}

This study found low EC of all forms of MNH visits (4ANC visits, institutional delivery, and $\mathrm{PNC}$ visit) compared to contact coverage of respective coverage of $\mathrm{MNH}$ visit. For example, in Nepal, contact coverage of 4ANC visits, institutional delivery and first PNC visits was $71 \%, 64 \%$ and $51 \%$ respectively [53], but EC was lower than these figures. These suggest that women are reaching to HFs but not receiving all essential interventions. Yet, while contact coverage of routine $\mathrm{MNH}$ visits is essential on its own it is inadequate to avert MMR and NMR.

Poor EC of MNH visits identified in the current study are consistent with the studies conducted in Bangladesh [54], Cambodia [55], and other LMICs of South Asia and Sub Saharan Africa [18, 46]. Studies conducted in Nepal reported poor quality of ANC [48] and had low uptake of recommended antenatal interventions (e.g., ANC counselling or iron or tetanus toxoid injections) [56]. An analysis of multi-country data revealed low EC of facility delivery [57] and 4ANC visits and PNC visit [58] despite high contact coverage of respective $\mathrm{MNH}$ visits. Few studies also reported poor EC of other health services such as treatment of sick children (e.g., treatment of diarrhoea, pneumonia) [46] and family planning services [23, 46]. In addition to challenges in reaching to HFs, poor EC coverage may have contributed by the health system's weakness, such as poor readiness, including a lack of trained health workers, or shortages of medicine for $\mathrm{MNH}$ services. 
The current study identified several determinants associated with $\mathrm{EC}$ of routine $\mathrm{MNH}$ services including ethnic and geographic disadvantage, Maithili speaking women, birth order, and gender of health care providers. First, in Nepal, ethnicity and socioeconomic status are associated with power and position in the society [59, 60]. Women with upper-caste groups usually have higher wealth status, usually are Nepali native speaker, they get a good opportunity for education and employment and are likely to have better awareness of health matters and the availability of health services. Disadvantaged ethnicities belong to the lower strata of the hierarchical caste system of Nepal [61]. Women with economic and ethic disadvantages have poor access to health services in Nepal [62]. Health programs should focus on disadvantaged ethnicities and design context-specific strategies to provide effective health services to those groups.

Secondly, women of province six had poor EC that could be contributed by scattered settlements, poor transportation facilities with limited access to reach HFs [63]. Reaching HFs is problematic due to limited road networks and poor transportation facilities $[64,65]$. Women's access to HFs can be improved via local development approaches such as constructing HFs in strategic locations and connecting community and health facilities by constructing bridges and road networks. However, these are non-health sector interventions that require multisectoral actions. Third, non-native Nepali speaker women, for instance, Maithili speaking women, usually have poor access to information. Poor access to health information might have contributed due to their low literacy rate [66]. Health education and information programs are not available in the local language, which affects health literacy among disadvantaged groups. In some cases, women cannot express their health care needs to health services providers if they could not understand Nepali or if health providers are unable to speak local languages. Recruitment of local health workforce and health education interventions conducted in local language can increase the uptake of $\mathrm{MNH}$ interventions.

Fourthly, women with high birth order (four or more) had poor EC of MNH visits in their recent pregnancy and childbirth. If women have more children, they may not prioritise the latest pregnancy and might not take the recommended $\mathrm{MNH}$ interventions in their pregnancy and childbirth [67]. Effective family planning services 
could reduce the number of birth order $[67,68]$. Women with wanted pregnancy visit health facility and take recommended $\mathrm{MNH}$ interventions for a healthy pregnancy and healthy childbirth. Fifth, some women prefer female providers for the uptake of MNH services in Nepal. Female health care providers can understand the need for health service users, and evidence indicates the provision of female providers can improve access to health services [69]. Similarly, if women receive good quality ANC, they are more likely to receive good quality institutional delivery services or PNC visit [37]. Improved quality of care is also likely to increase subsequent utilisation of MNH visits [56]. In nutshell, both access and health system response approaches care likely to improve EC of routine MNH visits. These approaches include equipping HFs with adequate supplies, trained health workers (e.g., local health workers who can understand local language and culture) and respectful maternity care and improved awareness on uptake of quality pregnancy, childbirth, and postnatal care from HFs.

This study demonstrated the measurement of the EC of routine $\mathrm{MNH}$ visits using NDHS data. The quality of care is emphasised in global health policies and universal access to quality MNH services SDG3 [9]; evaluating EC however, requires a population level measurement of quality of care. The EC of MNH visits can provide a proxy indicator of quality of care and go beyond simply contact coverage. This is important as evidence suggests access to health services alone cannot result in the intended MNH outcomes [13,70]. Measurement of quality of care requires multiple sources of data, such as users, providers, facility inventory, and observation of interaction between providers and users [9, 71]. This study also demonstrates, however, a single source of data can be used to assess the health care quality. This study assessed the EC of routine MNH visits taking information on services users' engagement with the health system and using data of household survey and information on adequate care, timely care, and frequent and skilled care while women visit health facilities.

\section{Policy and programmatic implications of the study}

This study has implications for policies and programs. Firstly, the EC has been an important concept for its applicability in health system performance and could be instrumental in tracking the progress towards universal health coverage of $\mathrm{MNH}$ services [17]. Secondly, in Nepal, monitoring systems have given limited attention to 
measuring the EC of health services including MNH services [72]. The methods used to estimate to assess the EC could provide ideas for the measurement of quality of health services. Thirdly, the universal coverage of quality $\mathrm{MNH}$ services are essential and need to focus on the quality of care for the reduction of NMR and MMR. To achieve SDG3 targets, the programmatic and policy focus should be beyond the contact coverage of $\mathrm{MNH}$ visits as only improving access to health services or contact coverage could not result in intended better MNH outcomes. Finally, this study identified disadvantaged women who were getting poor $\mathrm{EC}$ of $\mathrm{MNH}$ visits and identified the need for targeted approaches for effective uptake of $\mathrm{MNH}$ interventions among those groups. Programs and policies should focus on women with poor wealth status and ethnic disadvantages, and women speaking Maithili as the first language. Context-specific program approaches require to receive essential MNH interventions and ultimately improve the $\mathrm{EC}$ of $\mathrm{MNH}$ visits.

\section{Limitations of the study}

This study has some limitations. Firstly, data were self-reported, and thus, recall bias may occur. However, this study restricted to analysis among women who had a live birth in the two years prior to the survey (2014-2016), which is a relatively shorter recall period than other studies published using NDHS datasets in the past.

Secondly, outcome variables were self-reported by women during face-to-face interviews, which may lead to recall bias and social desirability bias. Thirdly, assessment of EC was limited by the information of $\mathrm{MNH}$ interventions available in the NDHS 2016. The NDHS did not collect information on all the WHOrecommended essential $\mathrm{MNH}$ interventions [4, 5, 45]. This study emphasises the importance of collecting information on MNH interventions in NDHS or routine HMIS system.

\section{Conclusions}

The uptake of recommended $\mathrm{MNH}$ interventions was low in all routine $\mathrm{MNH}$ visits (4 ANC visits, institutional delivery, and the first PNC visit) in Nepal. Poor EC of MNH visits was observed among women with social disadvantages, including those with ethnic disadvantage and living in remote areas. Both supply and demand-side multisectoral actions are needed to address several social determinants of health affecting poor EC of MNH visits in Nepal. Supply-side strategies such as recruiting female health providers and providing health commodities in HFs could improve the 
health system responses for delivery of better quality MNH services. Improving the status of social determinant of health, community engagement, and health awareness through mass media on the antenatal, childbirth, and postnatal period could increase the demand of services for EC of routine MNH visits. Non- health sector interventions could improve the $\mathrm{EC}$ of routine $\mathrm{MNH}$ visits, including arranging transportation facilities or constructing local bridge and roads to reach HFs. Health policies and programs should focus on women with socioeconomic disadvantages and living in remote areas.

\title{
Supplementary file 1
}

Supplementary Table S1: Description of variables included in the analysis of effective coverage of routine MNH visits in Nepal, 2016

Supplementary Table S2: Uptake of interventions during MNH visits in Nepal, 2016 Supplementary Table S3: Bivariable binomial logistic regression analysis for good $\mathrm{EC}$ of $\mathrm{MNH}$ visits in Nepal

\begin{abstract}
Abbreviations
ANC: Antenatal Care; CoC: Continuum of care; EC: Effective Coverage; LMICs: Low and lower-middle-income countries; MNH: Maternal and newborn health; NDHS: Nepal Demographic and Health Survey; PNC: Postnatal Care; SDIP: Safe Delivery Incentive Program
\end{abstract}

\section{Declaration}

\section{Ethics approval and consent to participate}

We used secondary data from the 2016 NDHS. This survey was approved by an ethical review board of Nepal Health Research Council, Nepal, and ICF Marco International, Maryland, USA. The Ministry of Health and Population (MOHP) (Nepal) oversaw the overall research process of the NDHS 2016. The NDHS data are publicly available for further analysis, and data were deidentified of the research participants. This study did not require ethical approval from respective institutions. However, the first author took approval for the download and use of the dataset for his doctoral thesis and this publication.

\section{Consent for publication}


Not applicable

\section{Availability of data and materials}

Data used in this study are publicly available secondary data obtained from the DHS (https://dhsprogram.com/data/available-datasets.cfm) program.

\section{Competing interests}

The authors declared that they have no competing interests.

\section{Funding}

No funding received for the development of this manuscript.

\section{Acknowledgements}

This manuscript is a part of the first author's doctoral thesis at the School of Public Health, the University of Queensland, supported by the University of Queensland International Scholarship and Career Development Extension Scholarship, and Research and Training Program Scholarship. The author would like to acknowledge the University of Queensland for providing the scholarship for the doctoral program. I would like to acknowledge Melinda Protani and Elisabeth Winkler for data analysis.

\section{Authors' contributions}

Design of the research, statistical analysis, interpretation: RBK. Writing first draft of manuscript: RBK and JD. Supervision of the study: RK, JD and YA. RBK, RK, JD and YA contributed significantly during the revision and finalised the manuscript. All authors read and agreed on the final version of the manuscript. 


\section{References}

1. WHO: Trends in maternal mortality 2000 to 2017: estimates by WHO, UNICEF, UNFPA, World Bank Group and the United Nations Population Division. In. WHO Geneva,; 2019.

2. $\quad \mathrm{Ng} \mathrm{M}$, Fullman N, Dieleman JL, Flaxman AD, Murray CJ, Lim SS: Effective coverage: a metric for monitoring universal health coverage. PLoS Med 2014, 11(9):e1001730.

3. Amouzou A, Leslie HH, Ram M, Fox M, Jiwani SS, Requejo J, Marchant T, Munos MK, Vaz LME, Weiss W et al: Advances in the measurement of coverage for RMNCH and nutrition: from contact to effective coverage. BMJ Glob Health 2019, 4(Suppl 4):e001297.

4. WHO: WHO recommendations on antenatal care for a positive pregnancy experience: World Health Organization; 2016.

5. WHO: Compilation of WHO recommendations on maternal, newborn, child and adolescent health. In. Geneva; 2013.

6. World Health Organization: WHO recommendations on postnatal care of the mother and newborn: World Health Organization; 2014.

7. WHO \& UNICEF: Pregnancy, childbirth, postpartum and newborn care: A guide for essential practice. In. Geneva; 2015.

8. Marsh AD, Muzigaba M, Diaz T, Requejo J, Jackson D, Chou D, Cresswell JA, Guthold R, Moran AC, Strong KL et al: Effective coverage measurement in maternal, newborn, child, and adolescent health and nutrition: progress, future prospects, and implications for quality health systems. Lancet Glob Health 2020, 8(5):e730-e736.

9. Kruk ME, Gage AD, Arsenault C, Jordan K, Leslie HH, Roder-DeWan S, Adeyi O, Barker P, Daelmans B, Doubova SV et al: High-quality health systems in the Sustainable Development Goals era: time for a revolution. Lancet Glob Health 2018, 6(11):e1196-e1252.

10. Koulidiati JL, Nesbitt RC, Ouedraogo N, Hien H, Robyn PJ, Compaore P, Souares A, Brenner S: Measuring effective coverage of curative child health services in rural Burkina Faso: a cross-sectional study. BMJ Open 2018, 8(5):e020423.

11. Darmstadt GL: Global perinatal health: accelerating progress through innovations, interactions, and interconnections. Semin Perinatol 2010, 34(6):367-370.

12. Darmstadt GL, Walker N, Lawn JE, Bhutta ZA, Haws RA, Cousens S: Saving newborn lives in Asia and Africa: cost and impact of phased scale-up of interventions within the continuum of care. Health Policy Plan 2008, 23(2):101-117.

13. Blanc AK, Diaz C, McCarthy KJ, Berdichevsky K: Measuring progress in maternal and newborn health care in Mexico: validating indicators of health system contact and quality of care. BMC Pregnancy Childbirth 2016, 16(1):255.

14. Barros AJ, Ronsmans C, Axelson H, Loaiza E, Bertoldi AD, Franca GV, Bryce J, Boerma JT, Victora CG: Equity in maternal, newborn, and child health interventions in Countdown to 2015: a retrospective review of survey data from 54 countries. Lancet 2012, 379(9822):1225-1233.

15. Huda TM, Hayes A, Dibley MJ: Examining horizontal inequity and social determinants of inequality in facility delivery services in three South Asian countries. J Glob Health 2018, 8(1):010416. 
16. Kim H, Novakovic $U$, Muntaner $\mathrm{C}$, Hawkes MT: A critical assessment of the ideological underpinnings of current practice in global health and their historical origins. Glob Health Action 2019, 12(1):1651017.

17. Jannati A, Sadeghi V, Imani A, Saadati M: Effective coverage as a new approach to health system performance assessment: a scoping review. BMC Health Serv Res 2018, 18(1):886.

18. Hodgins $S$, D'Agostino A: The quality-coverage gap in antenatal care: toward better measurement of effective coverage. Glob Health Sci Pract 2014, 2(2):173-181.

19. Martinez S, Carrasquilla G, Guerrero R, Gomez-Dantes H, Castro V, ArreolaOrnelas $\mathrm{H}$, Bedregal $\mathrm{P}$ : Effective coverage of health interventions in Latin America and the Caribbean: metrics for the assessment of health systems performance. Salud Publica Mex 2011, 53 Suppl 2:s78-84.

20. Heredia-Pi I, Servan-Mori E, Darney BG, Reyes-Morales H, Lozano R: Measuring the adequacy of antenatal health care: a national crosssectional study in Mexico. Bull World Health Organ 2016, 94(6):452-461.

21. McCollum R, Taegtmeyer M, Otiso L, Mireku M, Muturi N, Martineau T, Theobald S: Healthcare equity analysis: applying the Tanahashi model of health service coverage to community health systems following devolution in Kenya. Int J Equity Health 2019, 18(1):65.

22. Shibanuma A, Yeji F, Okawa S, Mahama E, Kikuchi K, Narh C, Enuameh Y, Nanishi K, Oduro A, Owusu-Agyei S et al: The coverage of continuum of care in maternal, newborn and child health: a cross-sectional study of woman-child pairs in Ghana. BMJ Glob Health 2018, 3(4):e000786.

23. Nguhiu PK, Barasa EW, Chuma J: Determining the effective coverage of maternal and child health services in Kenya, using demographic and health survey data sets: tracking progress towards universal health coverage. Trop Med Int Health 2017, 22(4):442-453.

24. Akseer N, Kamali M, Arifeen SE, Malik A, Bhatti Z, Thacker N, Maksey M, D'Silva $\mathrm{H}$, da Silva IC, Bhutta ZA: Progress in maternal and child health: how has South Asia fared? BMJ 2017, 357:j1608.

25. MOHP [Nepal]: Nepal demographic and health survey 2016. In. Kathmandu; 2017.

26. MOHP [Nepal]: Nepal health sector strategy 2015-2020. In. Kathmandu,; 2015.

27. MOHP [Nepal] National health policy 2019. In. Kathmandu; 2019.

28. FWD: Nepal Safe Motherhood and Newborn Health Road Map 2030. In. Kathmandu Ministry of Health and Population, Government of Nepal,; 2019

29. National Planning Commission, 2015: Sustainable Development Goals, 2016-2030, National Report. Government of Nepal, National Planning Commission, Kathmandu, Nepal

30. MOHP [Nepal]: Annual Report, Department of Health Services 2075/2076 (2018/2019). In.: Ministry of Health and Population. Kathmandu, Nepal. Ministry of Health and Population, Department of Health Services.; 2020.

31. NHSSP M: Report on Stocktaking the Health Policies of Nepal. In.: Nepal Health Sector Support Programme III; 2018.

32. Paudel M, Javanparast S, Dasvarma G, Newman L: A critical account of the policy context shaping perinatal survival in Nepal: policy tension of socio-cultural versus a medical approach. BMC Health Serv Res 2019, 19(1):166. 
33. Karkee $\mathrm{R}$, Lee $\mathrm{AH}$, Khanal V: Need factors for utilisation of institutional delivery services in Nepal: an analysis from Nepal Demographic and Health Survey, 2011. BMJ Open 2014, 4(3):e004372.

34. Khanal V, Adhikari M, Karkee R, Gavidia T: Factors associated with the utilisation of postnatal care services among the mothers of Nepal: analysis of Nepal demographic and health survey 2011. BMC Womens Health 2014, 14(1):19.

35. Mehata S, Paudel YR, Dariang M, Aryal KK, Paudel S, Mehta R, King S, Barnett S: Factors determining satisfaction among facility-based maternity clients in Nepal. BMC Pregnancy Childbirth 2017, 17(1):319.

36. Panth $A$, Kafle $P$ : Maternal satisfaction on delivery service among postnatal mothers in a government hospital, mid-western Nepal. Obstet Gynecol Int 2018, 2018:4530161.

37. Khatri RB, Karkee R: Social determinants of health affecting utilisation of routine maternity services in Nepal: a narrative review of the evidence. Reprod Health Matters 2018, 26(54):32-46.

38. Conway K, Akseer N, Subedi RK, Brar S, Bhattarai B, Dhungana RR, Islam $\mathrm{M}$, Mainali $\mathrm{A}$, Pradhan $\mathrm{N}$, Tasic $\mathrm{H}$ et al: Drivers of stunting reduction in Nepal: a country case study. Am J Clin Nutr 2020.

39. Mahato PK, Waithaka E, van Teijlingen E, Pant PR, Biswas A: Social autopsy: a potential health-promotion tool for preventing maternal mortality in low-income countries. WHO South East Asia J Public Health 2018, 7(1):24-28.

40. WHO: A conceptual framework for action on the social determinants of health. In. Geneva: World Health Organization; 2010.

41. World Health Organization: A conceptual framework for action on the social determinants of health. 2010.

42. Adewuyi EO, Auta A, Khanal V, Bamidele OD, Akuoko CP, Adefemi K, Tapshak SJ, Zhao Y: Prevalence and factors associated with underutilization of antenatal care services in Nigeria: A comparative study of rural and urban residences based on the 2013 Nigeria demographic and health survey. PLoS One 2018, 13(5):e0197324.

43. Khatri RB, Poudel S, Ghimire PR: Factors associated with unsafe abortion practices in Nepal: Pooled analysis of the 2011 and 2016 Nepal Demographic and Health Surveys. PLoS One 2019, 14(10):e0223385.

44. WHO: Definition of skilled health personnel providing care during childbirth. In.: World Health Organization; 2018.

45. WHO: WHO recommendations on postnatal care of the mother and newborn. In. Geneva; 2014.

46. Leslie $\mathrm{HH}$, Malata A, Ndiaye $\mathrm{Y}$, Kruk ME: Effective coverage of primary care services in eight high-mortality countries. BMJ Glob Health 2017 , 2(3):e000424.

47. Sharma J, Leslie HH, Kundu F, Kruk ME: Poor quality for poor women? Inequities in the quality of antenatal and delivery care in Kenya. PLOS One 2017, 12(1):e0171236.

48. Adhikari M, Chalise B, Bista B, Pandey AR, Upadhyaya DP:

Sociodemographic correlates of antenatal care visits in Nepal: results from Nepal Demographic and Health Survey 2016. BMC Pregnancy Childbirth 2020, 20(1):513. 
49. Akinwande MO, Dikko HG, Samson A: Variance Inflation Factor: As a Condition for the Inclusion of Suppressor Variable(s) in Regression Analysis. Open Journal of Statistics 2015, 05(07):754-767.

50. Heinze G, Wallisch C, Dunkler D: Variable selection - A review and recommendations for the practicing statistician. Biom J 2018, 60(3):431449.

51. Bursac Z, Gauss CH, Williams DK, Hosmer DW: Purposeful selection of variables in logistic regression. Source Code Biol Med 2008, 3:17.

52. Lemes IR, Sui X, Fernandes RA, Blair SN, Turi-Lynch BC, Codogno JS, Monteiro HL: Association of sedentary behavior and metabolic syndrome. Public Health 2019, 167:96-102.

53. Khatri RB: Towards equity of maternal and newborn health services in Nepal. PhD Thesis. The University of Queensland, Australia; 2021.

54. Nguyen PH, Khương LQ, Pramanik P, Billah SM, Menon P, Piwoz E, Leslie $\mathrm{HH}$ : Effective coverage of nutrition interventions across the continuum of care in Bangladesh: insights from nationwide cross-sectional household and health facility surveys. BMJ Open 2021, 11(1):e040109.

55. Benova L, Tunçalp Ö, Moran AC, Campbell OMR: Not just a number: examining coverage and content of antenatal care in low-income and middle-income countries. BMJ Global Health 2018, 3(2):e000779.

56. Joshi C, Torvaldsen S, Hodgson R, Hayen A: Factors associated with the use and quality of antenatal care in Nepal: a population-based study using the demographic and health survey data. BMC Pregnancy Childbirth 2014, 14:94.

57. Wang W, Mallick L, Allen C, Pullum T: Effective coverage of facility delivery in Bangladesh, Haiti, Malawi, Nepal, Senegal, and Tanzania. PLoS One 2019, 14(6):e0217853.

58. Carvajal-Aguirre L, Amouzou A, Mehra V, Ziqi M, Zaka N, Newby H: Gap between contact and content in maternal and newborn care: An analysis of data from 20 countries in sub-Saharan Africa. J Glob Health 2017, 7(2):020501.

59. Yadav UK, Ghimire P, Amatya A, Lamichhane A: Factors Associated with Anemia among Pregnant Women of Underprivileged Ethnic Groups Attending Antenatal Care at Provincial Level Hospital of Province 2, Nepal. Anemia 2021, 2021.

60. Paudel YR, Jha T, Mehata S: Timing of first antenatal care (ANC) and inequalities in early initiation of ANC in Nepal. Front Public Health 2017, 5:242.

61. Subedi M: Caste system: Theories and practices in Nepal. Himalayan Journal of Sociology and Anthropology 2010, 4:134-159.

62. Gellner DN: Caste, ethnicity and inequality in Nepal. Economic and Political Weekly 2007:1823-1828.

63. Kathmandu N: Maternal and Child Health in Nepal: The Effects of Caste, Ethnicity, and Regional Identity. 2013.

64. Pandey JP: Maternal and child health in Nepal: the effects of caste, ethnicity, and regional identity: further analysis of the $2011 \mathrm{Nepal}$ demographic and health survey; 2013.

65. Byrne A, Hodge A, Jimenez-Soto E, Morgan A: Looking beyond supply: a systematic literature review of demand-side barriers to health service 
utilization in the mountains of Nepal. Asia Pac J Public Health 2013, 25(6):438-451.

66. CBS [Nepal]: National population and housing census 2011. In.; 2012.

67. Thapa NR: Factors influencing the use of reproductive health services among young women in Nepal: analysis of the 2016 Nepal demographic and health survey. Reproductive Health 2020, 17(1):102.

68. Bhandari R, Pokhrel KN, Gabrielle N, Amatya A: Long acting reversible contraception use and associated factors among married women of reproductive age in Nepal. PLoS One 2019, 14(3):e0214590.

69. Napit K, Shrestha KB, Magar SA, Paudel R, Thapa B, Dhakal BR, Amatya A: Factors associated with utilization of adolescent-friendly services in Bhaktapur district, Nepal. J Health Popul Nutr 2020, 39(1):2.

70. Randive B, Diwan V, De Costa A: India's conditional cash transfer programme (the JSY) to promote institutional birth: is there an association between institutional birth proportion and maternal mortality? PLoS One 2013, 8(6):e67452.

71. Donabedian A: The quality of care. How can it be assessed? JAMA 1988, 260(12):1743-1748.

72. MOHP [Nepal]: Annual health report. In.; 2019. 


\section{Supplementary Files}

This is a list of supplementary files associated with this preprint. Click to download.

- supplimentaryfile.doc 